\title{
Correlation between contraction ratio, endurance, and muscle tone of cervical muscles
}

\author{
Ji-Hee Hong ${ }^{(1)}$, Dong-Hyeon Lee ${ }^{(1)}$, Seong-Eun Kim ${ }^{(i)}$, Dong-kwon Seo ${ }^{(1)}$ \\ Department of Physical Therapy, Konyang University, Daejeon, Republic of Korea
}

Objective: The endurance and strength of deep neck flexor (DNF) muscles have a major role on the function and stability of the cervical spine. In recent years, there has been a lack of research that have investigated the muscle tone of the superficial neck muscles. The purpose of this study was to examine the relationship of between contraction ratio of the DNF and sternocleidomastoid (SCM) muscles, DNF endurance, and muscle tension of the neck muscles.

Design: Cross-sectional study.

Methods: Forty-seven subjects (male $=20$, female=27) participated in this study. The muscle tone of the upper trapezius $($ UT), $\mathrm{SCM}$, and suboccipital (SO) muscle was measured using a contact soft tissue tone-measuring instrument. For the contraction ratio of the SCM and longus colli muscle, the thickness of the relaxation and maximum contraction state of the SCM and longus colli muscles were assessed using a diagnostic ultrasound measuring instrument and a pressure biofeedback unit. The deep neck flexor endurance test (DNFET) was performed in a cranio-cervical flexion posture. The correlations between the measured variables were investigated.

Results: The relationship between the DNFET and SO tone showed a significant negative correlation $(p<0.05)$. The relationship between the DNFET and contraction ratio showed a significant positive correlation $(p<0.01)$. There was no significant correlation between the DNFET and SCM and UT tone.

Conclusions: This study confirmed that there is a relationship between DNF endurance, DNF activation, and SO tone. The information on the results of this study may be used as a reference that can be actively applied in the clinical environment.

Key Words: Endurance, Muscle tonus, Neck muscle, Ultrasonography

\section{Introduction}

In most modern people, the time spent in assuming a forward head posture increases, which causes an overload to the soft tissues that support the neck, and as the amount of overload placed onto the neck continues, there is a greater negative effect on neck stability [1]. The forward head posture leads to weakening of the deep neck flexor and shortening of the suboccipital muscles, and promotes the elongation of the upper trapezius, and semispinalis capitis muscles, which can all lead to abnormal muscle activity in the flexor and extensor muscles [2,3]. Chronic forward head posture and minor damage accumulated in the neck cause mechanical dysfunction and chronic neck pain, and has a high recurrence rate [4]. Chronic neck pain is a decrease in activity and delayed activation of the deep neck flexor muscles, leading to a decrease in automatic feedforward, which subsequently leads to decreased neck stabilization and function $[5,6]$. The deep neck flexor and the suboccipital muscles are located in the deep part of the neck where they primarily maintain neck stability and work to create a normal alignment of the cervical spine, thus a normal posture of the neck [7]. The deep neck flexor muscle is composed of the deep longus capitis and colli, and is a muscle located deeper with-

Received: 31 August, 2020 Revised: 24 September, 2020 Accepted: 28 September, 2020

Corresponding author: Dong-kwon Seo (ORCID https://orcid.org/0000-0002-3328-4922)

Department of Physical Therapy, Konyang University, 158 Gwanjeodong-ro, Seo-gu, Daejeon 35365, Republic of Korea

Tel: 82-42-600-8457 Fax: 82-42-600-8408 E-mail: dkseo77@konyang.ac.kr

(c) This is an Open-Access article distributed under the terms of the Creative Commons Attribution Non-Commercial License (http://creativecommons.org/licenses/ by-nc/4.0) which permits unrestricted non-commercial use, distribution, and reproduction in any medium, provided the original work is properly cited.

Copyright @ 2020 Korean Academy of Physical Therapy Rehabilitation Science 
in the cervical vertebra than the sternocleidomastoid. It helps stabilize the cervical spine while the neck moves and and plays an important role in posture control [8-10]. The suboccipital muscles coantain a number of muscle spindles and maintains the stability of the cervical spine by controlling the rotational movements of the head and adjusting head posture [11]. Atrophy of the suboccipital muscles lead to a loss of balance, causing problems in postural stability [12].

An abnormal forward head posture restrains cervical spinal flexion and increases the extension of the upper cervical spine, resulting in significantly shorter suboccipital muscles, decreased activation of the long neck muscles, and significant increase in the thickness of the sternocleidomastoid (SCM) compared to normal subjects $[13,14]$. The endurance of the deep neck flexor muscle directly affects the function of the cervical spine, and the strength of these muscles is important in maintaining the posture and stability of the neck [15-17]. In a previous study, it was confirmed that the endurance and strength of the deep neck flexor muscles were decreased in patients with neck pain compared to normal subjects $[18,19]$. In addition, through a study using ultrasound imaging, it was proved that there was a negative correlation between the deep neck flexors and the SCM in patients with neck pain $[18,20]$.

As such, studies on the activity of the deep neck flexor and other cervical muscles have been actively conducted, and their correlation was verified through ultrasound images or superficial EMG studies. In a recent study, it was found that the degree of tension of the suboccipital muscles had a significant correlation with the angle of the head and the vertebrae, but did not have a significant correlation with the muscle endurance of the deep neck flexor muscle [21].

Measuring muscle tone is an easy method for evaluating the state of the muscle and has a high reliability. As such, the deep neck flexor and suboccipital muscles are being actively studied by focusing on changes in activity, but studies investigating neck muscle tension, although it can be easily evaluated, are insufficient,

Therefore, the purpose of this study was to investigate the relationship between the strength, endurance, and muscle activity of the deep neck flexor muscles and the tension of the adjacent cervical muscles, including the suboccipital muscles, and to search and provide objective information.

\section{Methods}

\section{Participants}

The number of study subjects was calculated using the G-power program, and 42 subjects were calculated by applying the effect size (Cohen's $d)=0.5$, power $=0.8$, and significance level $=0.05$. Considering the dropout rate, the number of study subjects was 47 .

The subjects of this study were 50 male and female college students in their twenties who were enrolled in $\mathrm{K}$ University in D city and had no neck disease. The criteria for selection of the subjects were: those who were capable of full range of active joint motion in the neck without pain, and those who could maintain a supine position without pain for more than 20 minutes. The exclusion criteria were: those who have been medically diagnosed as a disease, those who had a concussion diagnosis record, those who had experience with back or neck spine surgery, and those who had participated in a tug-pulling exercise program. Due to 3 subjects withdrawing from the study during the study period, data from 47 subjects were analyzed.

\section{Procedures}

In this study, 47 subjects were presented with the experimental procedures and after explaining the purpose and method of this study, consent to participate in the experiment was obtained by receiving informed consent and personal information. This study was conducted with the approval of the Bioethics Committee of Konyang University (KYU2019-299-01).

After receiving information on the general characteristics of the subjects, four measurements were performed. First, muscle tone of the upper trapezius (UT), sternocleidomastoid (SCM), and the suboccipital (SO) muscles were assessed. Second, the diastolic and systolic muscle thickness of the oblique and long neck muscles were assessed using ultrasound images. Third, muscle endurance of the deep neck flexor muscles were measured. Each data was analyzed and the results were presented.

\section{Outcome measure}

The muscle tone of the neck muscles was measured using a contact-type soft tissue analyzer (MyotonPRO, Estonia, Tallinn, 2014). Muscle tone was measured three times by having the ceramic part contacting the contact area at 90 degrees for each part, and after 3 measurements, the average value was set as the final measurement value, and a 
10 -second break was provided between each measurement.

Practice in the measurement process was conducted for one month to obtain consistent muscle tone measurements, and errors were minimized by maintaining the same posture and pressure. To measure the tension of the UT, the subject was asked to sit in a correct, upright posture with the legs placed out of the bed with their knees flexed to 90 degrees. The evaluator palpated the spinous processes and peaks of C7 and marked them with an aqueous marker at the central point that connects horizontally, and the point was measured using a contact-type soft tissue-measuring device. The subject was asked to lay supine on the bed in order to measure the tension of the SCM. The evaluator marked the central point connecting the mastoid process and the clavicle horizontally with an aqueous marker, and then measured the tension using a contact soft tissue-measuring device. In order to measure the tension of the suboccipital muscles, the subject was asked to lay in prone position on a bed where the face could be placed. After adjusting the height of the subject's face to make it inclined to 30 degrees in the shape of ' $\neg$ ', the evaluator palpated between the $\mathrm{C} 2$ spinous process and the central point of the back of the skull and marked it with a water-based marker. The marked point was measured for tension with a contact-type playing tissue measuring instrument. The measuring tool was established in previous studies to show high reliability (ICC 3,1>0.90) in terms of intra-measurement reliability and (ICC 3,2>0.70) in terms of inter-day reliability [22].

For the measurement of the longus colli and SCM thickness, the muscle thickness was measured in a contracted and relaxed state using an ultrasonic diagnostic instrument (Sonoview; Samsung, Seoul, Korea, 2017). Ultrasound measurements were performed using a stabilizer biofeedback unit to measure the diastolic pressures of $20 \mathrm{mmHg}$ and systolic pressures of 22, 24, 26, 28, and $30 \mathrm{mmHg}$. Prior to ultrasonic measurement, the C5-6 segments were positioned to set the measurement location. It was marked with an aqueous marker at a location $2 \mathrm{~cm}$ lateral to the trachea. After that, the thickness of the SCM and longus colli muscles were measured three times at a pressure of 20, 22, 24, 26, 28, and $30 \mathrm{mmHg}$ at that point, and the best resolution picture was selected.

In the selected photos, the SCM was measured from the lower part of the subcutaneous tissue to the upper inner wall edge of the artery, and the deep neck flexor muscle was measured to the lower inner wall edge of the artery. The average value was set as the measured value based on the area with the greatest change of the three lines of thickness. The analysis value was calculated as the maximum contraction thickness of each individual/diastolic $(20 \mathrm{mmHg})$ thickness $=$ contraction ratio. For the measurement posture, the subject was placed on a bed with a cushion under the knee, with the hip joint and knee flexed and looking up at the ceiling. A biological feedback device was placed under the neck, and the subject was instructed to lift the pressure gauge so that they could see the pressure gauge directly. Before the measurement, cranio-cervical flexion posture education was conducted, ultrasound was used to measure the muscles while they were contracted and maintained in the chin pull posture for each pressure. A 30-second break was provided after each pressure measurement.

In previous studies, the ultrasonic measurement method showed high reliability with ICC $0.83-0.89$ [23]. In this study, the contraction ratio of the deep neck flexor muscle and the SCM with a pressure of $26 \mathrm{mmHg}$ was used [20]. The endurance of the deep neck flexor muscles were measured through the deep neck flexor endurance test. Subjects were asked to lay in supine on a bed with a cushion under their knees to create hip and knee flexion. Subjects were asked to look up at the ceiling while a water-based marker was used to mark the skin wrinkles on the neck created from the vertical direction of the pull. Prior training was conducted twice before measurement. As for the measurement method, the back portion of the subject's head was lifted in a chin pulling state so that the subject's back was slightly touched (about $2.5 \mathrm{~cm}$ ). At this time, the subject was to

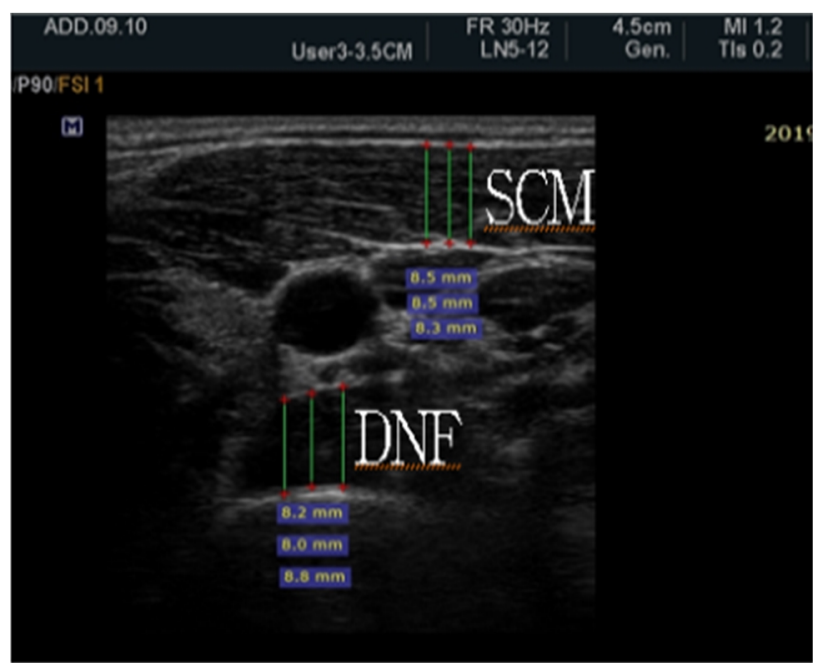

Figure 1. Ultrasound imaging. SCM: sternocledoimastoid muscle, DNF: longus colli muscle. 
maintain the chin pulling position so that the marked line between the skin folds before the measurement did not fall off. The holding time was taken as a measured value.

Measurements were performed after a 5-minute break was provided between each measurement. If the skin folds were widened or the position of the head maintained was changed, then the measurement process was terminated. The intra-measure reliability (ICC) of the deep neck flexion muscle endurance test varied from good to excellent, from 0.82 to 0.91 , and the inter-measurement reliability was 0.67 to 0.78 , showing a moderate to good level [9].

\section{Statistical analysis}

The data collected in this study were statistically processed using SPSS version 20.0 for Windows. Descriptive statistics were used to confirm the general characteristics of the subjects.

In this study, the Spearman analysis method of bivariate correlation analysis was used to confirm the correlation of each variable based on the normality test result. The stat- istical significance level was set to 0.05 or less.

\section{Results}

Table 1 shows the general characteristics of the subjects of this study. Table 2 shows the muscle thickness and contraction ratio of the subject's DNF and SCM for each pressure, and Table 3 shows the average value of the study subject's muscle tone and endurance. As a result of analysis of

Table 3. Muscle tone and endurance

$(\mathrm{N}=47)$

\begin{tabular}{lccc}
\hline & Male $(\mathrm{n}=20)$ & Female $(\mathrm{n}=27)$ & Total $(\mathrm{n}=47)$ \\
\hline UT. tone $(\mathrm{Hz})$ & $17.82\left(2.26^{\mathrm{a}}\right)$ & $17.69(1.50)$ & $17.74(1.84)$ \\
SCM. tone $(\mathrm{Hz})$ & $13.55(1.38)$ & $12.91(0.90)$ & $13.18(1.16)$ \\
SO. tone $(\mathrm{Hz})$ & $15.20(1.79)$ & $16.68(2.25)$ & $16.05(2.18)$ \\
Endurance $(\mathrm{sec})$ & $35.63(18.37)$ & $15.50(7.98)$ & $24.07(16.63)$ \\
\hline
\end{tabular}

Values are presented as mean (SD).

UT: upper trapezius, SCM: sternocleidomastoid, SO: suboccipital muscle.

Table 1. General characteristic of subjects

$(\mathrm{N}=47)$

\begin{tabular}{lllll}
\hline \multicolumn{1}{c}{ Subject } & Age $(\mathrm{y})$ & Weight $(\mathrm{kg})$ & Height $(\mathrm{cm})$ & BMI $\left(\mathrm{kg} / \mathrm{m}^{2}\right)$ \\
\hline Male $(\mathrm{n}=20)$ & $22.60\left(2.09^{\mathrm{a}}\right)$ & $79.16(14.95)$ & $175.80(5.01)$ & $25.59(4.69)$ \\
Female $(\mathrm{n}=27)$ & $20.19(4.33)$ & $56.94(9.89)$ & $161.67(4.33)$ & $21.73(3.25)$ \\
Total $(\mathrm{n}=47)$ & $21.21(8.42)$ & $66.40(16.46)$ & $167.68(8.42)$ & $23.37(4.33)$ \\
\hline
\end{tabular}

Values are presented as mean (SD).

Table 2. Muscle thickness and contraction ratio of DNF and SCM

$(\mathrm{N}=47)$

\begin{tabular}{|c|c|c|c|c|c|c|}
\hline & $20 \mathrm{mmHg}$ & $22 \mathrm{mmHg}$ & $24 \mathrm{mmHg}$ & $26 \mathrm{mmHg}$ & $28 \mathrm{mmHg}$ & $30 \mathrm{mmHg}$ \\
\hline \multicolumn{7}{|l|}{ Male $(n=20)$} \\
\hline DNF (mm) & $9.69\left(1.64^{\mathrm{a}}\right)$ & $10.28(1.44)$ & $9.63(1.37)$ & $9.71(1.37)$ & $9.86(1.38)$ & $9.79(1.56)$ \\
\hline D. ratio & 1 & $1.075(0.164)$ & $1.006(0.140)$ & $1.008(0.075)$ & $1.026(0.103)$ & $1.012(0.039)$ \\
\hline $\mathrm{SCM}(\mathrm{mm})$ & $8.27(1.17)$ & $8.13(1.01)$ & $8.20(1.07)$ & $8.23(1.12)$ & $8.25(1.14)$ & $8.26(1.15)$ \\
\hline S. ratio & 1 & $0.986(0.049)$ & $0.993(0.025)$ & $0.997(0.012)$ & $0.998(0.006)$ & $0.999(0.003)$ \\
\hline \multicolumn{7}{|l|}{ Female $(n=27)$} \\
\hline DNF (mm) & $7.85(1.17)$ & $7.85(1.20)$ & $7.25(1.73)$ & $7.66(1.27)$ & $7.87(1.15)$ & $7.97(1.12)$ \\
\hline D. ratio & 1 & $1.007(0.124)$ & $0.933(0.220)$ & $0.985(0.165)$ & $1.011(0.150)$ & $1.024(0.147)$ \\
\hline $\mathrm{SCM}(\mathrm{mm})$ & $6.30(1.11)$ & $6.32(1.04)$ & $6.25(1.04)$ & $6.31(1.08)$ & $6.29(1.08)$ & $6.27(1.09)$ \\
\hline S. ratio & 1 & $1.008(0.086)$ & $0.996(0.053)$ & $1.002(0.023)$ & $0.999(0.014)$ & $0.997(0.021)$ \\
\hline \multicolumn{7}{|l|}{ Total $(n=47)$} \\
\hline DNF (mm) & $8.63(1.65)$ & $8.88(1.77)$ & $8.26(1.97)$ & $8.53(1.65)$ & $8.72(1.59)$ & $8.75(1.59)$ \\
\hline D. ratio & 1 & $1.036(0.145)$ & $0.964(0.192)$ & $0.995(0.134)$ & $1.017(0.130)$ & $1.019(0.113)$ \\
\hline $\mathrm{SCM}(\mathrm{mm})$ & $7.14(1.49)$ & $7.09(1.36)$ & $7.08(1.43)$ & $7.13(1.45)$ & $7.13(1.47)$ & $7.12(1.48)$ \\
\hline S. ratio & 1 & $0.999(0.072)$ & $0.995(0.043)$ & $1.000(0.019)$ & $0.999(0.011)$ & $0.998(0.016)$ \\
\hline
\end{tabular}

Values are presented as mean (SD).

Ratio $=$ (muscle thickness of each contraction pressure/muscle thickness of resting pressure), resting pressure $=20 \mathrm{mmHg}$.

DNF: deep neck flexor, SCM: sternocleidomastoid muscle. 
Table 4. Correlation of the Endurance, Contraction Ratio, muscle tone

$(\mathrm{N}=47)$

\begin{tabular}{|c|c|c|c|c|c|c|}
\hline & Endurance & UT. tone & SCM. tone & SO. tone & $\begin{array}{l}\text { DNF ratio } \\
(26 \mathrm{mmHg})\end{array}$ & $\begin{array}{c}\text { SCM ratio } \\
\text { (26 mmHg) }\end{array}$ \\
\hline Endurance & 1 & & & & & \\
\hline UT. tone & -0.052 & 1 & & & & \\
\hline SCM. tone & 0.050 & 0.202 & 1 & & & \\
\hline SO. tone & $-0.321^{*}$ & 0.059 & 0.153 & 1 & & \\
\hline DNF ratio $(26 \mathrm{mmHg})$ & $0.375^{* *}$ & 0.243 & -0.197 & -0.076 & 1 & \\
\hline $\mathrm{SCM}$ ratio $(26 \mathrm{mmHg})$ & 0.016 & 0.148 & -0.099 & 0.148 & 0.007 & 1 \\
\hline
\end{tabular}

Values are presented as Mean (SD).

UT: upper trapezius, SCM: sternocleidomastoid, SO: suboccipital muscle, DNF: deep neck flexor contraction ratio, SCM: sternocleidomastoid muscle contraction ratio.

${ }^{*} p<0.05,{ }^{*} p<0.01$.

the correlation between muscle contraction, muscle endurance, and muscle tone of the study subjects, muscle endurance showed a statistically significant negative correlation with the tension of the subocciptal muscles $(p<0.05)$, and there was a statistically significant positive correlation between muscle endurance and contracility of the deep neck flexor muscle $(p<0.01)$ (Table 4$)$.

\section{Discussion}

The deep neck flexors play an important role in providing postural control and neck stability [10], and the contraction force and muscle endurance of the deep neck flexors show a significant correlation with those with neck pain [19]. In general, during the deep neck flexor muscle endurance test, the deep neck flexor muscle is activated, and the SCM and anterior scalene muscles become relative [24,25]. In addition, through studies using ultrasound imaging, it was proved that in patients with neck pain or subjects with forward head posture, there was a negative correlation with the deep neck flexor muscle and the SCM [20].

As such, while ultrasound imaging and surface EMG studies are being actively conducted, studies confirming the correlation between muscle contraction force and muscle endurance have been lacking despite the high reliability of muscle tone studies. Therefore, in this study, the relationship between the muscle thickness of the deep and thin neck muscles and the muscle endurance and muscle tone of the deep neck muscles was examined.

The contact-type soft tissue measuring instrument used in this study is a non-invasive measuring instrument that can quickly and easily measure the relaxation and tension of muscles and soft tissues without pain, and it has the advant- age of being able to measure the UT, SCM, and suboccipital muscles in a variety of positions [26,27]. The deep neck flexor muscle endurance test is a reliable, cost-effective, and useful clinical tool for the prevention and treatment of neck pain [17,28]. A diagnostic ultrasonic measuring device was used to measure the muscle thickness to determine the contractile force of the deep flexor and SCM muscles. The diagnostic ultrasound meter is a non-invasive test method performed at a low cost and a wide range of applications, and is the most basic test method among muscle imaging tests. In addition, there is an advantage that it is possible to observe the muscles in real time and to measure the state of relaxation and contraction of the muscles [20]. In this study, the contraction ratio of the deep neck flexor and the SCM was 26 mmHg. A study by Ishida et al. [20] reported that the efficiency of measuring the activity of the deep neck flexor and SCM muscless was high at $26 \mathrm{mmHg}$ and $28 \mathrm{mmHg}$.

As a result of this study, muscle endurance showed a significant positive correlation with the contractility of the deep neck flexor muscle $(p<0.01)$. There was no correlation with the SCM contraction force.

A recent study suggested that the deep neck flexor muscle endurance had a significant correlation, and the SCM muscle had no correlation, supporting the results of this study [18].

In the previous study, the endurance of the deep neck flexor muscle was significantly decreased in persons with forward head posture compared to the normal persons [29].

Javanshir et al. [19] reported that the thickness of the SCM muscle of subjects with neck pain was smaller than that of the normal subjects. In this way, it can be seen that when there is neck pain, muscle contraction and muscle endurance are reduced at the same time compared to normal 
people. Considering this reason, it can be seen that there is a positive correlation with the contractile forces of the deep neck flexor and muscular endurance.

As a result of this study, there was a significant negative correlation between muscle endurance and muscle tone of the subocciptal muscles, and the contractile force of the deep neck flexor muscles was not significantly correlated with the tension of the SCM and suboccipital muscles.

In a previous study, the forward head posture decreased the flexion of the head and cervical spine, resulting in decreased activation of the deep neck flexor and shortening of the suboccipital muscles [2].

Most of the shortened muscles were reported to have elevated muscle tone [30]. In a previous study, patients with chronic neck pain showed a decrease in the activity of the pectoral muscles and an increase in the activity of the pectoral muscles in the deep neck flexor endurance test [31,32]. The pectoralis tendon is not attached to the cervical vertebra, but overactivation of the pectoralis tendon causes the upper cervical spine to extend and the inferior cervical spine to flex $[33,34]$. Comprehensive results of previous studies support the results that the lower the deep neck flexion muscle endurance, the higher the muscle tone of the suboccipital muscles.

The limitations of this study are as follows. First, it is difficult to generalize because the recruitment of candidates is limited to one university. Second, since this study included subjects in their twenties, additional research is needed that includes subjects of various age groups. There is the hope that research will be conducted on various populations in the future by supplementing these limitations, and additional research is necessary for patients with neck pain or subjects with forward head posture.

This study was conducted to study the correlation between muscle endurance of the neck, muscle contraction of the deep neck flexor and the SCM muscles, and the muscle tone of the UT, suboccipital and SCM muscles. As a result of this study, there was a positive correlation between muscular endurance and contractile force of the deep neck flexor muscles, and a negative correlation was found between muscular endurance and muscle tone of the suboccipital muscles.

Based on the results of this study, further studies examining the tension of the deep neck flexors and circumferential muscles in patients with forward head posture and neck pain are necessary. The results of this study may serve as useful information that can be utilized in a clinical environment.

\section{Conflict of Interest}

The authors declared no potential conflicts of interest with respect to the authorship and/or publication of this article.

\section{References}

1. Gong W. Impact of longus colli muscle massage on the strength and endurance of the deep neck flexor muscle of adults. J Phys Ther Sci 2013;25(5):591-3.

2. Griegel-Morris P, Larson K, Mueller-Klaus K, Oatis CA. Incidence of common postural abnormalities in the cervical, shoulder, and thoracic regions and their association with pain in two age groups of healthy subjects. Phys Ther 1992;72(6):425-31.

3. Finley MA, Lee RY. Effect of sitting posture on 3-dimensional scapular kinematics measured by skin-mounted electromagnetic tracking sensors. Arch Phys Med Rehabil 2003;84(4):563-8.

4. Blomgren J, Strandell E, Jull G, Vikman I, Roijezon U. Effects of deep cervical flexor training on impaired physiological functions associated with chronic neck pain: a systematic review. BMC Musculoskelet Disord 2018;19(1):415.

5. Falla D, Jull G, Edwards S, Koh K, Rainoldi A. Neuromuscular efficiency of the sternocleidomastoid and anterior scalene muscles in patients with chronic neck pain. Disabil Rehabil 2004; 26(12):712-7.

6. Falla D, Jull G, Hodges PW. Feedforward activity of the cervical flexor muscles during voluntary arm movements is delayed in chronic neck pain. Exp Brain Res 2004;157(1):43-8.

7. Kim JY, Kwag KI. Clinical effects of deep cervical flexor muscle activation in patients with chronic neck pain. J Phys Ther Sci 2016;28(1):269-73

8. Mayoux-Benhamou MA, Revel M, Vallée C, Roudier R, Barbet JP, Bargy F. Longus colli has a postural function on cervical curvature. Surgical and radiologic anatomy : SRA 1994;16(4): 367-71.

9. Harris KD, Heer DM, Roy TC, Santos DM, Whitman JM, Wainner RS. Reliability of a measurement of neck flexor muscle endurance. Phys Ther 2005;85(12):1349-55.

10. Harrison DE, Harrison DD, Betz JJ, Janik TJ, Holland B, Colloca $\mathrm{CJ}$, et al. Increasing the cervical lordosis with chiropractic biophysics seated combined extension-compression and transverse load cervical traction with cervical manipulation: nonrandomized clinical control trial. J Manipulative Physiol Ther 2003;26(3): 139-51.

11. Cho SH, Kim SH, Park DJ. The comparison of the immediate effects of application of the suboccipital muscle inhibition and self-myofascial release techniques in the suboccipital region on short hamstring. J Phys Ther Sci 2015;27(1):195-7.

12. Dugailly PM, Sobczak S, Moiseev F, Sholukha V, Salvia P, Feipel V, et al. Musculoskeletal modeling of the suboccipital spine: kinematics analysis, muscle lengths, and muscle moment arms during axial rotation and flexion extension. Spine (Phila Pa 1976) 2011;36(6):E413-22.

13. Bokaee F, Rezasoltani A, Manshadi FD, Naimi SS, Baghban AA, Azimi H. Comparison of cervical muscle thickness between 
asymptomatic women with and without forward head posture. Brazilian J Phys Ther 2017;21(3):206-11.

14. Jung S, Kwon O, Choi K, Ha S, Kim S, et al. Comparison of the Thickness of the Neck Flexor Muscles of Subjects With and Without a Forward Head Posture on the Two Initial Head Positions During Cranio-Cervical Flexion Exercise. Phys Ther Korea 2015;22(4):44-50.

15. Stemper BD, Yoganandan N, Pintar FA. Influence of muscle contraction on whiplash kinematics. Biomed Sci Instrum 2004;40: 24-9.

16. Sterling M, Jull G, Vicenzino B, Kenardy J, Darnell R. Development of motor system dysfunction following whiplash injury. Pain 2003;103(1-2):65-73.

17. Domenech MA, Sizer PS, Dedrick GS, McGalliard MK, Brismee JM. The deep neck flexor endurance test: normative data scores in healthy adults. PM R 2011;3(2):105-10.

18. Ghamkhar L, Kahlaee AH. Are Ultrasonographic Measures of Cervical Flexor Muscles Correlated With Flexion Endurance in Chronic Neck Pain and Asymptomatic Participants? Am J Phys Med Rehabil 2017;96(12):874-80.

19. Javanshir K, Rezasoltani A, Mohseni-Bandpei MA, Amiri M, Ortega-Santiago R, Fernandez-de-Las-Penas C. Ultrasound assessment of bilateral longus colli muscles in subjects with chronic bilateral neck pain. Am J Phys Med Rehabil 2011;90(4):293301.

20. Ishida H, Suehiro T, Ono K, Kurozumi C, Watanabe S. Correlation between deep cervical flexor muscle thickness at rest and sternocleidomastoid activity during the craniocervical flexion test. $\mathrm{J}$ Bodyw Mov Ther 2016;20(1):208-13.

21. Lee HJ, Lee JY, Jeong JY, Seo DK. Correlation between Tone of Suboccipital Muscle and Endurance of Deep Neck Flexor Muscle according to Angle Changes in College Students. J Korean Soc Phys Med 2019;14(2):137-44.

22. Aird L, Samuel D, Stokes M. Quadriceps muscle tone, elasticity and stiffness in older males: reliability and symmetry using the MyotonPRO. Arch Gerontol Geriatr 2012;55(2):e31-9.

23. Javanshir K, Mohseni-Bandpei MA, Rezasoltani A, Amiri M, Rahgozar M. Ultrasonography of longus colli muscle: A reli- ability study on healthy subjects and patients with chronic neck pain. J Bodyw Mov Ther 2011;15(1):50-6.

24. Amiri M, Jull G, Bullock-Saxton J, Darnell R, Lander C. Cervical musculoskeletal impairment in frequent intermittent headache. Part 2: subjects with concurrent headache types. Cephalalgia 2007;27(8):891-8.

25. O'Leary S, Cagnie B, Reeve A, Jull G, Elliott JM. Is there altered activity of the extensor muscles in chronic mechanical neck pain? A functional magnetic resonance imaging study. Arch Phys Med Rehabil 2011;92(6):929-34.

26. Kocur P, Grzeskowiak M, Wiernicka M, Goliwas M, Lewandowski J, Łochyński D. Effects of aging on mechanical properties of sternocleidomastoid and trapezius muscles during transition from lying to sitting position-A cross-sectional study. Arch Gerontol Geriatr 2017;70:14-8.

27. Park SK, Yang DJ, Kim JH, Heo JW, Uhm YH, Yoon JH. Analysis of mechanical properties of cervical muscles in patients with cervicogenic headache. J Phys Ther Sci 2017;29(2):332-5.

28. Olson LE, Millar AL, Dunker J, Hicks J, Glanz D. Reliability of a clinical test for deep cervical flexor endurance. J Manipulative Physiol Ther 2006;29(2):134-8.

29. Oliveira AC, Silva AG. Neck muscle endurance and head posture: A comparison between adolescents with and without neck pain. Man Ther 2016;22:62-7.

30. Gurfinkel V, Cacciatore TW, Cordo P, Horak F, Nutt J, Skoss R. Postural muscle tone in the body axis of healthy humans. J Neurophysiol 2006;96(5):2678-87.

31. Jull G, Kristjansson E, Dall'Alba P. Impairment in the cervical flexors: a comparison of whiplash and insidious onset neck pain patients. Man Ther 2004;9(2):89-94.

32. Sterling M, Jull G, Wright A. Cervical mobilisation: concurrent effects on pain, sympathetic nervous system activity and motor activity. Man Ther 2001;6(2):72-81.

33. Kamibayashi LK, Richmond FJ. Morphometry of human neck muscles. Spine (Phila Pa 1976) 1998;23(12):1314-23.

34. Vasavada AN, Li S, Delp SL. Influence of muscle morphometry and moment arms on the moment-generating capacity of human neck muscles. Spine (Phila Pa 1976) 1998;23(4):412-22. 